\title{
MICROAGREGADOS ESTÁVEIS E RESERVA DE NUTRIENTES EM LATOSSOLO VERMELHO SOB PASTAGEM EM REGIÃO DE CERRADO ${ }^{1}$
}

\author{
Diego Lang Burak ${ }^{2}$, Maurício Paulo Ferreira Fontes 3 , Thierry Becquer ${ }^{4}$
}

\begin{abstract}
STABLE MICROAGGREGATES AND NUTRIENT POOL IN OXISOL UNDER PASTURE IN SAVANNAH REGION

Nutrients preserved in microaggregates are an important fraction of the pool of nutrients in highly weathered soils. With the objective of better understanding the nutrients distribution in microaggregates of fine-sand $(200-50 \mu \mathrm{m})$ and coarse-silt $(50-20 \mu \mathrm{m})$, in a Rhodic Haplustox, the present study utilized an adapted physical fractionation procedure with mineralogical and chemical characterization. Part of the soil fractions was characterized as microaggregates formed by clay and silt minerals, with high macro and micronutrients contents. $\mathrm{P}, \mathrm{Cu}, \mathrm{Mn}$, and $\mathrm{Zn}$ were more efficiently accumulated in the microaggregates and less susceptive to removal by the weathering and leaching actions, when compared to $\mathrm{K}$ and $\mathrm{Mg}$. Higher $\mathrm{C}$ contents were found in the superficial horizon microaggregates $(50-20 \mu \mathrm{m})$, showing evidences of an efficient physical protection against mineralization. Macro and micronutrients pools (total contents), in the 200-50 $\mu \mathrm{m}$ and 50-20 $\mu \mathrm{m}$ microaggregates, corresponded to $5-19 \%$ of the total soil nutrients content, and $24-26 \%$ of the total soil carbon was seized by those microaggregates. Although these microaggregates present a low capacity to store nutrients, they become an important and highly stable compartment to preserve nutrients, as far as physical degradation and weathering and leaching are concerned.
\end{abstract}

KEY-WORDS: Soil aggregation; physical fractionation; macronutrients; micronutrients; organic matter storage.

\section{INTRODUÇÃO}

Nutrientes preservados em microagregados de latossolos com baixos teores de matéria orgânica podem contribuir, efetivamente, para sua fertilidade natural, devido à quantidade reduzida de minerais primários facilmente intemperizáveis (MPFI) presentes nestes solos. Este fato foi pioneiramente registrado por Moura Filho \& Buol (1976), que atribuíram a eutrofia encontrada em alguns Latossolos Vermelhos

\section{RESUMO}

Nutrientes preservados em microagregados podem constituir reserva importante em solos altamente intemperizados. Com o objetivo de melhor compreender a distribuição de nutrientes em microagregados contidos em frações granulométricas de $200-50 \mu \mathrm{m}$ e $50-20 \mu \mathrm{m}$, de um Latossolo Vermelho distrófico típico, utilizou-se um procedimento de fracionamento físico, adaptado para o objetivo deste estudo, em conjunto com análises químicas e mineralógicas. Parte destas frações foi caracterizada como microagregados constituídos por minerais da fração argila e silte, com altos teores de macro e micronutrientes. $\mathrm{P}, \mathrm{Cu}, \mathrm{Mn}$ e $\mathrm{Zn}$ foram mais eficientemente acumulados nos microagregados e menos susceptíveis à remoção, pela ação do intemperismo e lixiviação, em comparação ao K e $\mathrm{Mg}$. Maiores teores de $\mathrm{C}$ foram encontrados nos microagregados de 50-20 $\mu \mathrm{m}$ do horizonte superficial, devido à proteção física mais eficiente contra a mineralização. Os estoques de macro e micronutrientes (teores totais), nos microagregados (200-50 $\mu \mathrm{m}$ e 50-20 $\mu \mathrm{m})$, corresponderam a $5-19 \%$ do total de nutrientes no solo, e $24-26 \%$ do total de carbono do solo esteve sequestrado nestes microagregados. Apesar da baixa capacidade de reserva destes microagregados, eles tornam-se um compartimento de alta estabilidade, com maior eficiência na função de preservar os nutrientes, frente à degradação física e ao intemperismo e lixiviação.

PALAVRAS-CHAVE: Agregados do solo; fracionamento físico; macronutrientes; micronutrientes; estoque de matéria orgânica.

ao efeito protetor dos microagregados, os quais impedem ou diminuem as perdas de nutrientes decorrentes do processo de intemperismo e lixiviação.

A formação de microagregados está relacionada à gênese e mineralogia dos solos altamente intemperizados (Moura Filho \& Buol 1976, Ferreira et al. 1999, Muggler et al. 1999, Volland-Tuduri et al. 2004). Tal informação tem sido atribuída a processos físicos, geoquímicos e biológicos (Cooper et al. 2005). Expansão e contração são processos físicos

1. Trabalho recebido em jan./2010 e aceito para publicação em jun./2011 (nº registro: PAT 8771/ DOI: 10.5216/pat.v41i2.8771).

2. Universidade Federal do Espírito Santo, Departamento de Produção Vegetal, Alegre, ES, Brasil.E-mail: dlburak@hotmail.com.

3. Universidade Federal de Viçosa, Departamento de Solos, Viçosa, MG, Brasil.E-mail: mpfontes@ufv.br.

4. Institut de Recherche pour le Développement (IRD), Montpellier, France.E-mail: thierry.becquer@ird.fr. 
que geram fissuras no solo, facilitando a formação e estabilização dos microagregados (Trapnell \& Webster 1986).

A atividade biológica realizada pela mesofauna, particularmente formigas e cupins, origina microagregados, pela manipulação do solo, na construção de ninhos e canais (Schaeffer 2001). Com relação aos processos geoquímicos, diversas hipóteses são lançadas, nas quais as etapas de floculação e cimentação das partículas do solo, por componentes inorgânicos ou orgânicos do solo, são fundamentais (Tisdall \& Oades 1982, Cambier 1986, Schwertmann et al. 1986). Os agentes responsáveis pelos processos genéticos de formação de microagregados se diferenciam daqueles responsáveis pela formação de agregados de tamanhos maiores, em que a matéria orgânica do solo tem papel mais relevante (Tisdall \& Oades 1982). Desta forma, os agregados do solo podem ser divididos em micro e macroagregados.

Macroagregados são estruturas pedológicas definidas, com tamanho superior a $300 \mu \mathrm{m}$ (Balbino et al. 2002), $250 \mu \mathrm{m}$ (Azevedo \& Bonumá 2004) ou $200 \mu \mathrm{m}$ (Balabane \& Plane 2004), ao passo que os microagregados são menores (50-300 $\mu \mathrm{m})$ (Jastrow et al. 1996, Wan \& El-Swaify 1998, Six et al. 2002). No entanto, em algumas situações, frações com tamanho 50-2 $\mu \mathrm{m}$ podem ser incluídas nas classes dos microagregados, por não corresponderem a minerais da fração silte e sim a microagregados que podem desempenhar importantes funções de preservação da matéria orgânica e nutrientes (Virto et al. 2008).

Poucos trabalhos envolvendo solos tropicais enfatizam a presença de nutrientes em microagregados estáveis. Atualmente, trabalhos em âmbito nacional e internacional se direcionam ao papel da agregação do solo e seu efeito protetor sobre a matéria orgânica do solo, como uma forma de sequestro de carbono (C) (Six et al. 2002, Denef et al. 2004, Passos et al. 2007). A dinâmica do $C$ sequestrado pode ser diferenciada entre macro e microagregados. Contudo, um consenso existe sobre o fato de que os teores de $\mathrm{C}$ e nutrientes preservados nos microagregados são mais estáveis e, portanto, menos alterados com o manejo (Jastrow et al. 1996, Wan \& El-Swaify 1998).

Na região de Paracatu, noroeste de Minas Gerais, a necessidade de novas áreas para o uso agrícola aumenta anualmente, avançando, principalmente, sobre latossolos sob Cerrado, que apresentam relevo e propriedades físicas favoráveis à agricultura com alto nível tecnológico de manejo. Entretanto, o avanço da agricultura, em parte da região do Cerrado, tem sido realizado com práticas inadequadas de conservação do solo, resultando na quebra irreversível das estruturas pedológicas (Balbino et al. 2002). Neste contexto, apesar de diversos estudos serem direcionados à degradação do solo e sua consequência nas propriedades físicas do solo, poucas informações existem para a melhor compreensão do papel dos microagregados mais estáveis, como reserva de nutrientes e carbono, frente à degradação física do solo.

O presente trabalho teve como objetivo avaliar a capacidade de os microagregados estáveis de um Latossolo Vermelho distrófico típico da região dos Cerrados, em Paracatu (noroeste de MG), atuarem como reserva de carbono orgânico, macro e micronutrientes.

\section{MATERIAL E MÉTODOS}

O solo em estudo foi identificado e caracterizado em janeiro de 2004, sendo os procedimentos analíticos de fracionamento físico realizados em março/junho 2007. O perfil do solo estudado, desenvolvido sobre rochas pelíticas, com influência de rochas calcárias, na região de Paracatu (MG), foi descrito segundo Lemos \& Santos (2002) e classificado como Latossolo Vermelho distrófico típico. As amostras dos horizontes separados foram coletadas, secas ao ar e peneiradas em malha de $2 \mathrm{~mm}$ (TFSA). A caracterização química foi realizada nas amostras de TFSA, de acordo com a Embrapa (1997). Foram determinados o pH em água (relação 1:2,5); $\mathrm{K}$ trocável e $\mathrm{P}$ disponível, extraídos com a solução Mehlich-1; Al, Ca e Mg trocáveis, extraídos com $\mathrm{KCl}$ $1 \mathrm{~mol} \mathrm{~L}^{-1} ; \mathrm{e} \mathrm{Al}^{3+}+\mathrm{H}^{+}$, extraído com acetato de cálcio a $\mathrm{pH}$ 7. $\mathrm{O}$ fósforo remanescente foi determinado de acordo com Novais \& Smyth (1999). Para avaliação do carbono orgânico (CO), empregou-se o método da oxidação por dicromato de potássio e titulação com sulfato ferroso (Walkley \& Black 1934). A análise granulométrica foi realizada de acordo com método proposto pela Embrapa (1997).

O estudo do fracionamento físico foi conduzido somente em amostras dos horizontes Ap $(0-30 \mathrm{~cm})$ e $\mathrm{Bw}_{2}(110-160 \mathrm{~cm})$. O esquema de separação das diferentes frações granulométricas encontra-se na Figura 1, seguindo o método proposto por Balesdent et al. (1991), com algumas modificações. As etapas de fracionamento foram realizadas em triplicatas. As frações granulométricas foram separadas em função 

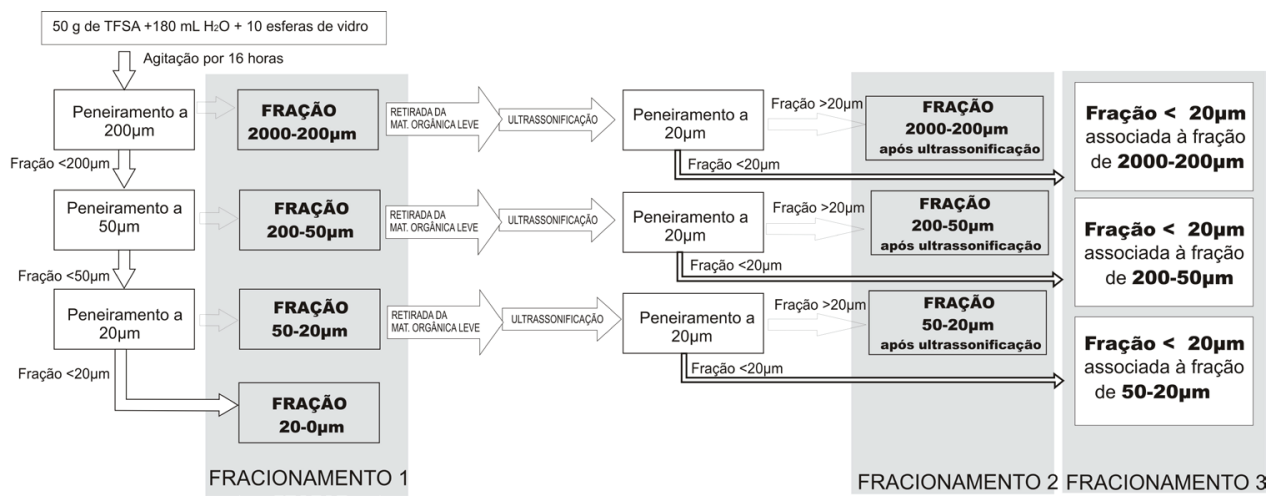

Figura 1. Esquema representativo do fracionamento físico utilizado.

do tamanho, após agitação em água deionizada, na ausência de dispersantes. As frações foram separadas nos seguintes tamanhos: 2.000-200 $\mu \mathrm{m}, 200-50 \mu \mathrm{m}$, $50-20 \mu \mathrm{m} \mathrm{e}<20 \mu \mathrm{m}$. Nestas frações, estão inclusos tanto os minerais das frações areia e silte como os agregados não destruídos com a agitação em água (Fracionamento 1; Figura 1). A argila não foi separada da fração $<20 \mu \mathrm{m}$, uma vez que o solo não se dispersa naturalmente em meio aquoso e a utilização de dispersantes químicos poderia promover remobilização de elementos entre as frações.

A Matéria Orgânica Leve (MOL) foi retirada das frações 2.000-200 $\mu \mathrm{m}, 200-50 \mu \mathrm{m}$ e 50-20 $\mu \mathrm{m}$, por flotação em água, após o procedimento do Fracionamento 1 (Figura 1) (Anderson \& Ingram 1989), correspondendo às raízes finas e restos vegetais presentes no solo ou dentro das estruturas pedológicas de tamanho superior a $20 \mu \mathrm{m}$. Nesta etapa, a utilização de soluções de densidade maiores que $1 \mathrm{~g} \mathrm{~cm}^{-3}$ foi evitada, pela possibilidade de mobilização dos nutrientes, por estas soluções, entre as diferentes frações estudadas. Após a retirada da MOL, as amostras foram submetidas a ultrassonificação, por 45 minutos, a $28 \mathrm{kHz}$ (equivalente a $500 \mathrm{~J} \mathrm{~mL}^{-1}$ ), objetivando-se a obtenção de agregados não destruídos pela agitação em água, sem afetar, no entanto, o tamanho das partículas de matéria orgânica. Roscoe et al. (2000) não observaram evidências de redistribuição física da matéria orgânica, utilizando energia superior a $800 \mathrm{~J} \mathrm{ml}^{-1}$, na separação por flotação. $\mathrm{O}$ material desagregado (argila + silte fino + matéria orgânica de tamanho $<20 \mu \mathrm{m}$ ) foi separado por peneira com malha de $20 \mu \mathrm{m}$, correspondendo à fração $<20 \mu \mathrm{m}$ do Fracionamento 3 (Figura 1). Após a etapa de ultrassonificação, obtiveram-se as frações com tamanho de 2.000-200 $\mu \mathrm{m}, 200-50 \mu \mathrm{m}$ e 50-20 $\mu \mathrm{m}$, livres de agregados, ou seja, minerais primários da fração areia grossa, areia fina e silte grosso, respectivamente (Fracionamento 2; Figura 1). Junto com estas frações, obteve-se a matéria orgânica de tamanho $>20 \mu \mathrm{m}$, oclusa nos agregados 2.000-200 $\mu \mathrm{m}, 200-50 \mu \mathrm{m}$ e 50-20 $\mu \mathrm{m}$.

Amostras de todas as frações separadas após trituração em almofariz de ágata foram digeridas em micro-ondas. A digestão foi realizada com $9 \mathrm{~mL}$ de $\mathrm{HNO}_{3}$ e $3 \mathrm{~mL}$ de $\mathrm{HF}$ concentrados, utilizando-se $0,5 \mathrm{~g}$ de amostras provenientes das triplicatas das etapas do fracionamento físico. Utilizou-se um procedimento de digestão em duas etapas: a primeira com aumento progressivo da temperatura até $170^{\circ} \mathrm{C}$ e potência máxima de $350 \mathrm{~W}$, por 15 minutos, e a segunda com temperatura fixa de $180^{\circ} \mathrm{C}$, por 5 minutos, e potência máxima de $350 \mathrm{~W}$. A dosagem dos macro ( $\mathrm{P}, \mathrm{Ca}$ e $\mathrm{Mg}$ ) e micronutrientes (Fe, $\mathrm{Mn}, \mathrm{Cu}$ e $\mathrm{Zn}$ ) foi feita por espectroscopia de emissão óptica, em plasma indutivamente acoplado. $\mathrm{O} \mathrm{K}$ foi determinado em espectroscopia de emissão em chama. Foi determinado o carbono total, por analisador elementar $\mathrm{CHN}$ da marca Perkin Elmer PE-2400 CHNS, das frações granulométricas e da matéria orgânica leve separada por flotação.

A análise mineralógica por difração de raios-X foi conduzida em amostras não orientadas das frações granulométricas. Objetivando-se à semiquantificação de alguns minerais, lâminas escavadas foram utilizadas para as frações de $200-50 \mu \mathrm{m}$ e $50-20 \mu \mathrm{m}$. Os difratogramas foram obtidos em aparelho Siemens D5000, com radiação de CoKa, operado a $40 \mathrm{kV}$ e 30 mA. A razão gibbsita/(gibbsita + caulinita), Gb/ $(\mathrm{Gb}+\mathrm{Ct})$, foi calculada pela relação entre a área (A) das reflexões $\mathrm{Gb}$ (002) e $\mathrm{Ct}(001)$ : AGb/(AGb + ACt) (Inda Júnior \& Kämpf 2003). Com o intuito de 
melhor avaliar a presença dos microagregados, observações das frações, antes e após o fracionamento físico, foram feitas em microscópio óptico de marca NIKON Eclipse E400 Pol, acoplado a uma câmera digital com aumento de x 40-200.

Os dados foram avaliados pelo teste $\mathrm{F}$, comparando-se somente o efeito da ultrassonificação (Fracionamento 1 x Fracionamento 2) nas frações granulométricas. Demais resultados foram avaliados pelo erro-padrão, que permite avaliar a precisão da estimativa obtida pela média.

\section{RESULTADOS E DISCUSSÃO}

\section{Caracterização do solo}

Os valores de $\mathrm{pH}$ dos horizontes superficiais (Ap, AB e BA) mantiveram-se na faixa moderadamente ácida e os horizontes subsuperficiais $\left(\mathrm{Bw}_{1}\right.$, $\mathrm{Bw}_{2}$ e $\mathrm{Bw}_{3}$ ) na faixa fortemente ácida (Embrapa 2006). Isto ocorre em razão da tendência de maiores valores de saturação de bases e menores teores de $\mathrm{Al}^{3+}$ trocável serem encontrados em superfície. Foram encontrados valores de saturação de bases (V) e saturação de alumínio (m), respectivamente, de $62 \%$ e $0 \%$, no horizonte Ap, e $29 \%$ e $64 \%$, no horizonte $\mathrm{Bw}_{1}$. O fósforo disponível variou entre $0,1 \mathrm{mg} \mathrm{dm}^{-3}$ e $1,6 \mathrm{mg} \mathrm{dm}^{-3}$, com maiores valores em superfície (Tabela 1). Fonseca et al. (2007) encontraram baixos valores de saturação de bases (7-9\%) e baixos teores de $\mathrm{P}$ (1,2-0,1 $\left.\mathrm{mg} \mathrm{dm}^{-3}\right)$ disponível no horizonte superficial de um Latossolo Vermelho distrófico sob cerradão, como tipicamente encontrado em solos dos Cerrados. Nesta região, os solos são geralmente poucos férteis em superfície e subsuperfície, sendo a maior saturação de bases do solo explicada, possivelmente, pela influência de rochas calcárias, no entorno.
A capacidade de troca cationnica total $(\mathrm{T})$ e o carbono orgânico (CO) variaram 4,7-10,52 $\mathrm{mol}_{c} \mathrm{dm}^{-3}$ e 0,3-1,95 dag $\mathrm{kg}^{-1}$, respectivamente, com menores valores nos horizonte subsuperficiais. Adicionalmente, em subsuperfície, ocorreram, também, os menores valores de fósforo remanescente (P-rem; 1,7-5,0 $\mathrm{mg} \mathrm{L}^{-1}$ ), indicando a presença de óxidos de $\mathrm{Fe}$ e Al. O P-rem indica a concentração de P que permanece em solução, após a adição de $60 \mathrm{mg} \mathrm{L}^{-1}$ de $\mathrm{P}$ ao solo (Novais \& Smyth 1999). Tal quantidade de $\mathrm{P}$ depende da capacidade de adsorção de fosfatos do solo, existindo relação direta de menores valores de P-rem com teores mais elevados de óxidos de $\mathrm{Fe}$ eAl e/ou presença menos efetiva de ácidos orgânicos bloqueando sítios de adsorção de fosfato (Novais \& Smyth 1999).

Na Tabela 2, são apresentadas as características morfológicas do Latossolo estudado. A cor indica a presença de óxidos de Fe, na composição mineralógica da fração argila. A estrutura foi caracterizada em superfície, como composta por blocos médios subangulares, em superfície, passando a forte, muito pequena, granular em profundidade, morfologia, esta, característica de latossolos (Ferreira et al. 1999, Volland-Tuduri et al. 2004). A partir da análise textural, o solo foi classificado como argiloso. A presença de óxidos, evidenciada pelo P-rem e cor, é comprovada pela estrutura tipicamente pequena, forte e granular, como observado em solos altamente intemperizados, de características mais oxídicas (Moura Filho \& Buol 1976, Ferreira et al. 1999, Volland-Tuduri et al. 2004).

\section{Distribuição e caracterização das frações no solo}

A fração $<20 \mu \mathrm{m}$ foi a mais abundante, em ambos os horizontes com menor participação das frações 200-50 $\mu \mathrm{m}$ e 50-20 $\mu \mathrm{m}$. Com a ultrassonificação,

Tabela 1. Resultado da caracterização química do solo estudado (Paracatu, MG, 2004).

\begin{tabular}{|c|c|c|c|c|c|c|c|c|c|c|c|c|c|}
\hline \multirow{3}{*}{ Horizonte } & \multirow{3}{*}{ Prof. } & \multirow{3}{*}{$\begin{array}{c}\mathrm{pH} \\
\left(\mathrm{H}_{2} \mathrm{O}\right)\end{array}$} & \multicolumn{8}{|c|}{ Complexo de troca } & \multirow{2}{*}{$\mathrm{CO}$} & \multirow{2}{*}{ P-disp } & \multirow{2}{*}{ P-rem } \\
\hline & & & $\mathrm{K}^{+}$ & $\mathrm{Ca}^{2+}$ & $\mathrm{Mg}^{2+}$ & $\mathrm{Al}^{3+}$ & SB & $\mathrm{T}$ & $\mathrm{V}$ & $\mathrm{m}$ & & & \\
\hline & & & \multicolumn{6}{|c|}{$\mathrm{cmol}_{\mathrm{c}} \mathrm{dm}^{-3}$} & \multicolumn{2}{|c|}{$-\%$} & dag kg-1 & $\mathrm{mg} \mathrm{dm}^{-3}$ & $\mathrm{mg} \mathrm{L}^{-1}$ \\
\hline Ap & $0-30$ & 5,9 & 0,59 & 3,90 & 2,02 & 0,00 & 6,51 & 10,52 & 62 & 0 & 1,95 & 1,6 & 22,10 \\
\hline $\mathrm{AB}$ & $30-40$ & 5,6 & 0,18 & 2,26 & 0,71 & 0,10 & 3,15 & 6,95 & 47 & 3 & 1,13 & 0,8 & 13,20 \\
\hline BA & $40-70$ & 5,4 & 0,13 & 1,22 & 0,47 & 0,48 & 1,82 & 6,32 & 36 & 20 & 0,67 & 0,5 & 8,70 \\
\hline $\mathrm{Bw}_{1}$ & $70-110$ & 5,3 & 0,13 & 0,23 & 0,19 & 0,96 & 0,55 & 5,15 & 29 & 64 & 0,45 & 0,2 & 5,00 \\
\hline $\mathrm{Bw}_{2}$ & $110-160$ & 5,2 & 0,12 & 0,45 & 0,24 & 0,39 & 0,81 & 4,91 & 24 & 32 & 0,30 & 0,1 & 1,70 \\
\hline $\mathrm{Bw}_{3}^{2}$ & $160+$ & 5,4 & 0,14 & 0,55 & 0,33 & 0,10 & 1,02 & 4,72 & 24 & 8 & 0,30 & 0,2 & 2,70 \\
\hline
\end{tabular}


Tabela 2. Resultado da caracterização morfológica do solo estudado (Paracatu, MG, 2004).

\begin{tabular}{|c|c|c|c|c|c|c|}
\hline \multirow{3}{*}{ Horizonte } & \multirow{3}{*}{ Profundidade } & \multirow{3}{*}{$\operatorname{Cor}^{1}$} & \multirow{3}{*}{ Estrutura $^{2}$} & \multicolumn{3}{|c|}{ Análise textural } \\
\hline & & & & Areia & Silte & Argila \\
\hline & & & & \multicolumn{3}{|c|}{ dag $\mathrm{kg}^{-1}$} \\
\hline Ap & $0-30$ & $5 Y R 3 / 3$ & $1-2, \mathrm{~m}, \mathrm{bs}$ & 36 & 22 & 48 \\
\hline $\mathrm{AB}$ & $30-40$ & $2,5 \mathrm{YR} 4 / 4$ & $1-2, \mathrm{p}-\mathrm{m}, \mathrm{bs}$ & 30 & 20 & 50 \\
\hline BA & $40-70$ & $2,5 \mathrm{YR} 4 / 6$ & $1, \mathrm{p}-\mathrm{m}, \mathrm{bs}$ & 25 & 19 & 56 \\
\hline $\mathrm{Bw}_{1}$ & $70-110$ & $2,5 \mathrm{YR} 4 / 7$ & $1, \mathrm{p}, \mathrm{bs}-3, \mathrm{p}, \mathrm{gr}$ & 29 & 17 & 54 \\
\hline $\mathrm{Bw}_{2}$ & $110-160$ & $2,5 \mathrm{YR} 4 / 8$ & $3, \mathrm{mp}, \mathrm{gr}$ & 34 & 18 & 48 \\
\hline $\mathrm{Bw}_{3}^{2}$ & $160+$ & 2,5 YR $5 / 8$ & $3, \mathrm{mp}, \mathrm{gr}$ & 24 & 18 & 58 \\
\hline
\end{tabular}

${ }^{1}$ Cores padronizadas pela caderneta de Munsell. ${ }^{2} 1$ - fraca; 2 - moderada; 3 - forte; mp - muito pequena; $\mathrm{p}$ - pequena; $\mathrm{m}$ - média; $\mathrm{g}$ - grande; gr - granular; bs - bloco subangular.

quantidades da fração $<20 \mu \mathrm{m}$ foram recuperadas das frações, como observado pela diferença significativa, a $5 \%$, pelo teste $F$, entre o Fracionamento 1 e 2, principalmente das frações 200-50 $\mu \mathrm{m}$ e 50-20 $\mu \mathrm{m}$. Diferença não significativa ocorreu na fração $2.000-200 \mu \mathrm{m}$, em ambos os horizontes (Figura 2). Atenção pode ser direcionada às expressivas diferenças no $\mathrm{Bw}_{2}$, nas frações 50-20 $\mu \mathrm{m}$, nas quais, aproximadamente, $20-30 \%$ em peso corresponde a frações menores que $20 \mu \mathrm{m}$, que estavam presentes como microagregados destruídos pela ultrassonificação, ou seja, 1,5-2,5\% do peso total do solo. Estes microagregados de tama-

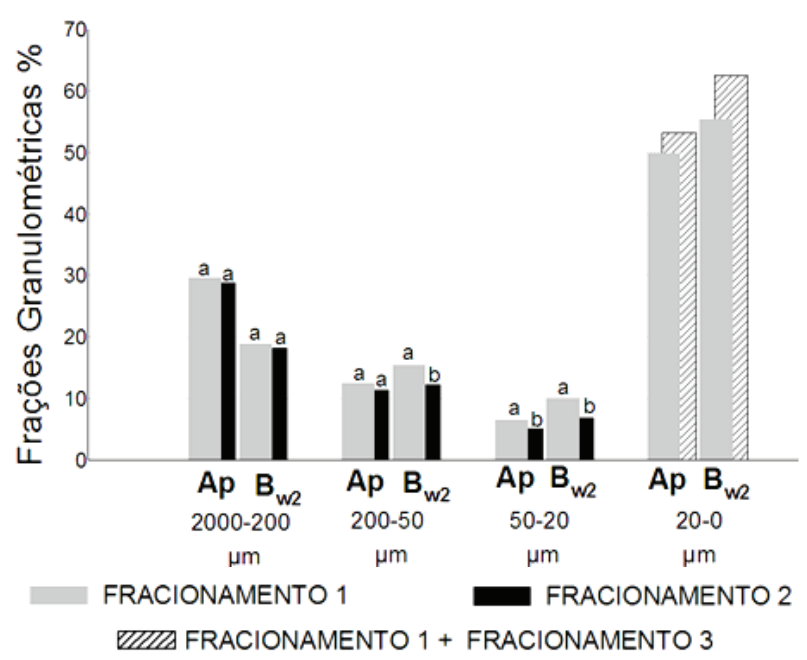

Figura 2. Distribuição percentual em massa das frações granulométricas de 2.000-200 $\mu \mathrm{m}, 200-50 \mu \mathrm{m}$ e 50-20 $\mu \mathrm{m}$, antes (Fracionamento 1) e após (Fracionamento 2), e da fração $<20 \mu \mathrm{m}$, obtida pela agitação em água, somada à fração $<20 \mu \mathrm{m}$, obtida pela ultrassonificação (Fracionamento $1+$ Fracionamento 3). Barras seguidas de diferentes letras são diferentes, significativamente, a $5 \%$, pelo teste $\mathrm{F}$ (Paracatu, MG, 2004). nho silte grosso e areia fina não são destruídos pelos procedimentos usualmente utilizados em análises granulométricas, principalmente em solos mais intemperizados e oxídicos (Donagemma et al. 2008).

As frações $<20 \mu \mathrm{m}$, associadas às frações 2.000-200 $\mu \mathrm{m}$ e retiradas pela ultrassonificação, estão relacionadas, principalmente, a revestimentos finos de argila sobre os grãos de areia, conforme observado em lupa binocular (dados não apresentados; Burak 2008). Donagemma (2000), avaliando microagregados estáveis, presentes mesmo após a dispersão, nos procedimentos de análise granulométrica, destaca microagregados mais abundantes nos tamanhos das frações silte $(50-2 \mu \mathrm{m})$ e areia fina $(200-50 \mu \mathrm{m})$ e menor participação dos microagregados no tamanho areia grossa $(2.000-200 \mu \mathrm{m})$

Para avaliação do efeito da ultrassonificação, nas frações $200-50 \mu \mathrm{m}$ e $50-20 \mu \mathrm{m}$, fotomicrografias foram realizadas, antes e após o procedimento (Figura 3). A fração 2.000-200 $\mu \mathrm{m}$ não revelou a presença de agregados (dados não apresentados; Burak 2008) e, por esta razão, não foi estudada, por serem enfatizados, no presente trabalho, microagregados de tamanho 200-20 $\mu \mathrm{m}$.

Microagregados arredondados e avermelhados são frequentes, antes da ultrassonificação (Figuras 3a e 3c), ocorrendo raramente após tal procedimento (Figuras 3b e 3d). Nas fotomicrografias apresentadas na Figura 3, os microagregados avermelhados, de tamanho 200-50 $\mu \mathrm{m}$ e 50-20 $\mu \mathrm{m}$, não destruídos pela agitação em água (Figuras 3a e 3c), são, de fato, as frações $<20 \mu \mathrm{m}$ recuperadas no Fracionamento 3 (Figura 1). A partir dos resultados da difração de raios-X, antes da ultrassonificação (Difratogramas A e C; Figura 3), pôde-se verificar a presença de gibbsita, goethita, caulinita e micas, compondo os 

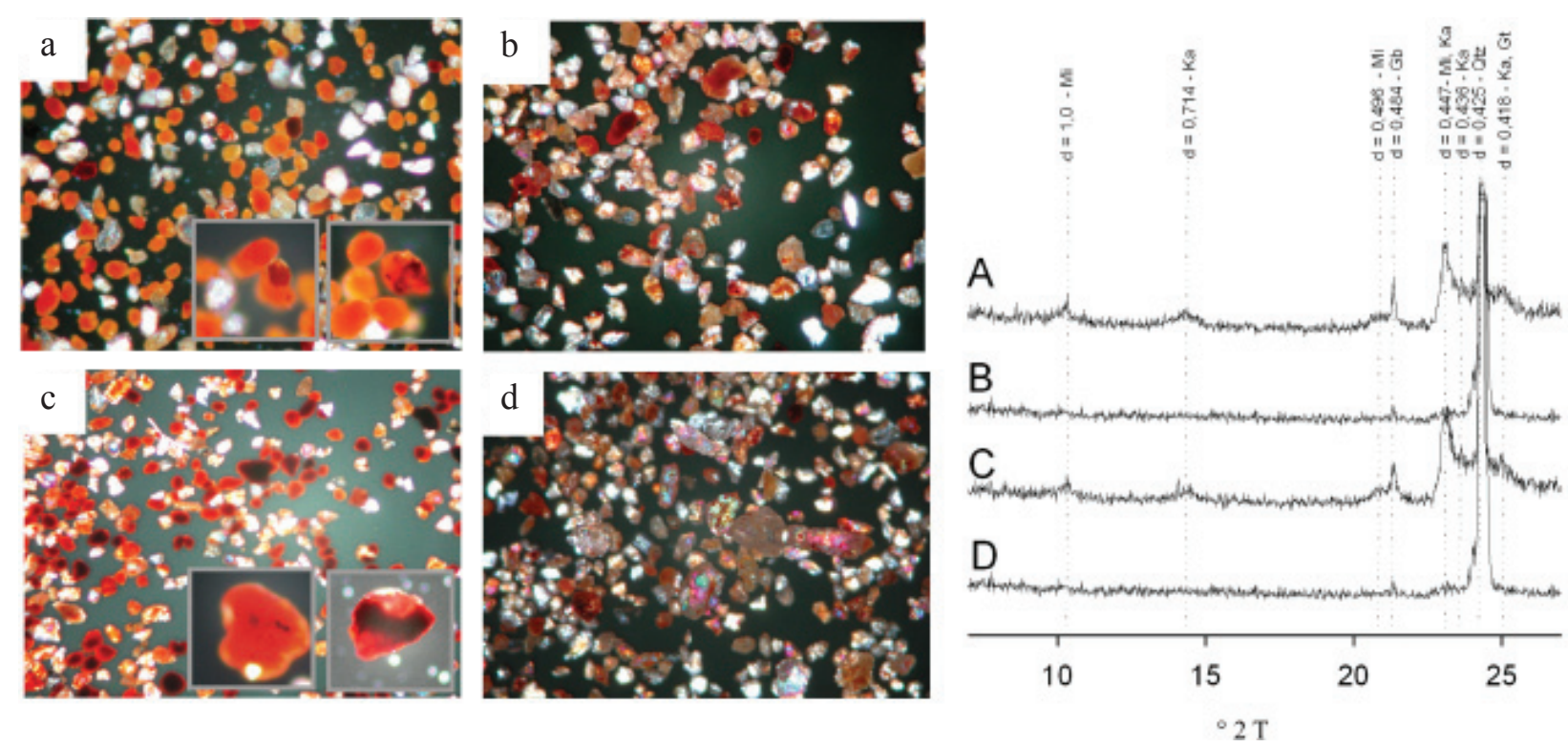

$\mathrm{Mi}=$ micas, $\mathrm{Ka}=$ caulinita, $\mathrm{Qtz}=$ quartzo, $\mathrm{Gth}=$ goethita, $\mathrm{Gb}=$ gibbsita

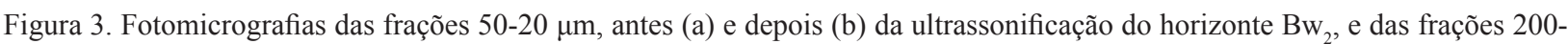
$50 \mu \mathrm{m}$, antes (c) e depois (d) da ultrassonificação do horizonte $\mathrm{Bw}_{2}$. Detalhe dos microagregados de tamanho 50-20 $\mu \mathrm{m}$ (quadro menor) (a) e 200-50 $\mu \mathrm{m}$ (quadro menor) (b). Difratogramas das análises de raios-X das frações 50-20 $\mu \mathrm{m}$, antes (a) e depois da ultrassonificação (b), e das frações 200-50 $\mu \mathrm{m}$, antes (c) e depois (d) da ultrassonificação, com os espaçamentos interplanares dos minerais identificados em nanômetros (Paracatu, MG, 2004).

microagregados avermelhados que foram observados em microscópio óptico. Após a ultrassonificação (Difratogramas B e D; Figura 3), os reflexos de raios-X dos minerais gibbsita, goethita, caulinita e micas são menos intensos e o quartzo foi predominante nas frações, indicando a menor presença de minerais primários facilmente intemperizáveis como reserva de nutrientes, na fração areia fina e silte grosso. Da mesma forma, os microagregados avermelhados estiveram menos presentes após a ultrassonificação (Figuras $3 \mathrm{~b}$ e $3 \mathrm{~d}$ ). A presença frequente destes microagregados, em solos altamente intemperizados, tem sido relacionada com a mineralogia rica em óxidos de Al (Ferreira et al. 1999) e óxidos de Fe (Muggler et al. 1999).

Análises de difração de raios-X foram conduzidas na fração $<20 \mu \mathrm{m}$, obtida por ultrassonificação da fração 50-20 $\mu \mathrm{m}$ (Fracionamento 3), e na fração $<20 \mu \mathrm{m}$, obtida por agitação em água (Fracionamento 1) (Figura 4). Os resultados dos difratogramas de raios-X mostram certa similaridade mineralógica entre estas duas frações. Porém, a partir da relação $\mathrm{Gb} /(\mathrm{Gb}+\mathrm{Ct})$, foram observados valores de 0,61 , para a fração $<20 \mu \mathrm{m}$, menos protegida fisicamente (obtida por agitação em água), e 0,85, para a fração $<20 \mu \mathrm{m}$, mais protegida fisicamente (obtida por ultrassonificação). Esta diferença, quanto à mineralogia, sugere a maior presença da caulinita do que gibbsita, na fração $<20 \mu \mathrm{m}$ intramicroagregado, possivelmente pela maior proteção física dentro destes microagregados, onde a ação do intemperismo químico é menos intensa, facilitando a permanência de minerais menos intemperizados, como a caulinita. Virto et al. (2008) conseguiram observar, por meio dos resultados das difrações de raios-X, que as frações oclusas em microagregados do tamanho 50-20 $\mu \mathrm{m}$ continham mais argilominerais (caulinita e minerais tipo 2:1) que as frações não oclusas nestes microagregados. No presente trabalho, pôde-se constatar maior intensidade de alguns reflexos, referentes a minerais tipo 2:1, na fração $<20 \mu \mathrm{m}$, obtida por ultrassonificação (Fracionamento 3), como, por exemplo, o reflexo a $52,3^{\circ} 2 \mathrm{~T}(\mathrm{~d}=2,01 \AA)$, referente a micas e ilitas $(\mathrm{d}=2,01 \AA)$ (Figura 4).

Teores de macro e micronutrientes nas frações granulométricas

Nas Figuras 5 e 6, são apresentados os teores de macro e micronutrientes, respectivamente, nas 


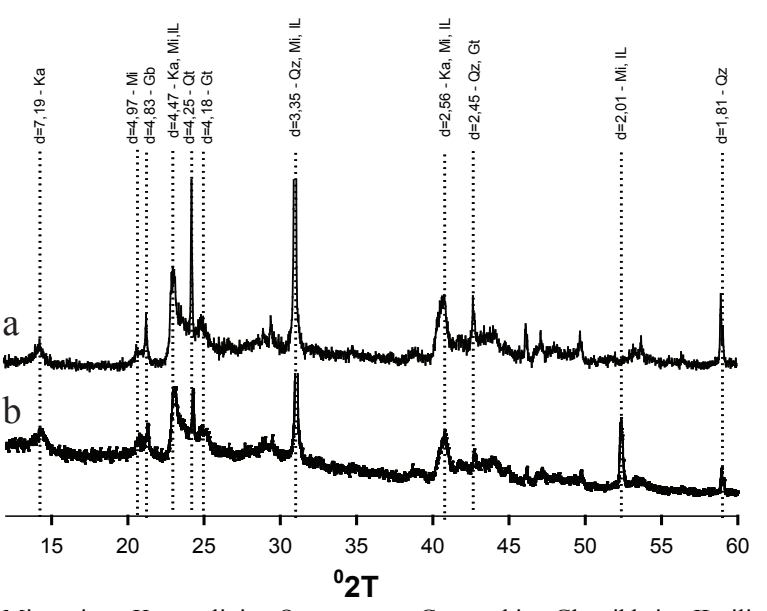

$\mathrm{Mi}=$ micas, $\mathrm{Ka}=$ caulinita, $\mathrm{Qtz}=$ quartzo, $\mathrm{Gt}=$ goethita, $\mathrm{Gb}=$ gibbsita, $\mathrm{IL}=$ ilita

Figura 4. Análises de raios-X das frações $<20 \mu \mathrm{m}$ (a), obtidas por agitação em água (matriz mineral menos protegida fisicamente - interagregados), e das frações $<20 \mu \mathrm{m}$ (b), obtidas por ultrassonificação (matriz mineral mais protegida fisicamente - intra-agregados), com os espaçamentos interplanares dos minerais identificados em angstroms (Paracatu, MG, 2004).
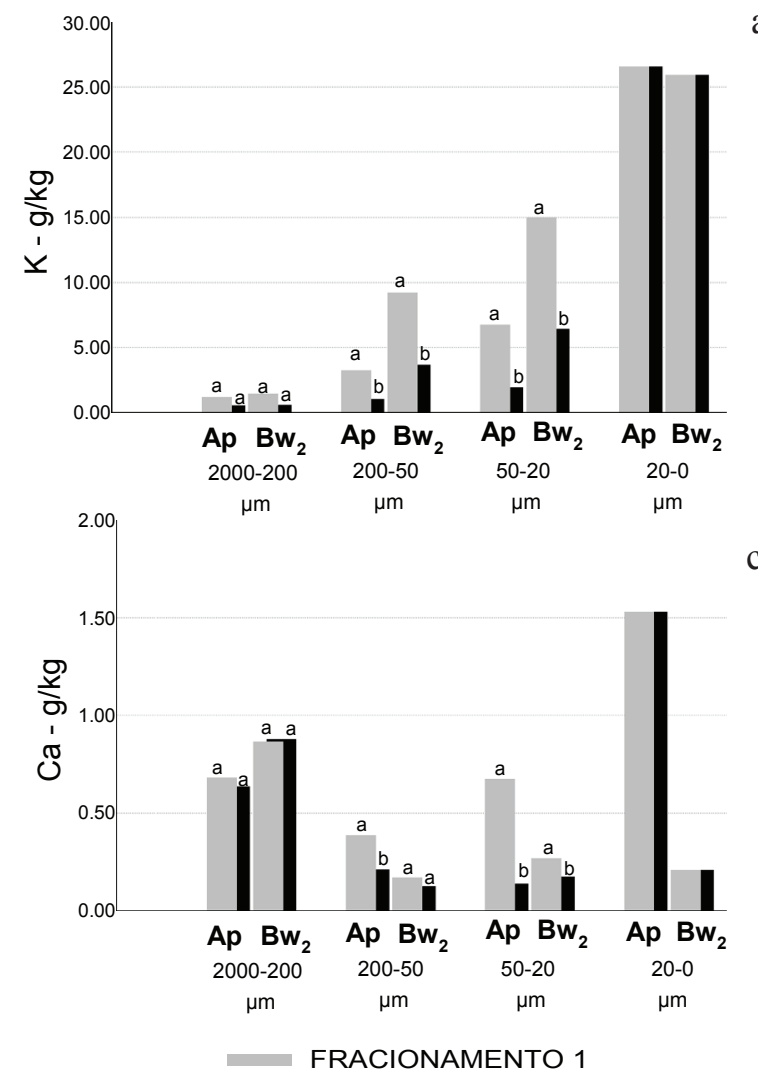

a frações antes e após o procedimento de ultrassonificação. Pode-se observar diferença não significativa (5\%; teste F) dos teores, na fração 2.000-200 $\mu \mathrm{m}$, e diferença significativa nas frações $200-50 \mu \mathrm{m}$ e 50-20 $\mu \mathrm{m}$, com o procedimento de ultrassonificação, indicando que grande parte dos nutrientes está associada a partículas mais finas, arranjadas na forma de microagregados estáveis (observados em microscópio), não desagregados pela agitação em água.

Após a ultrassonificação, é possível destacar os teores próximos a zero, das frações $50-20 \mu \mathrm{m}$, para o $\mathrm{P}\left(\mathrm{Ap} \mathrm{e} \mathrm{Bw}_{2}\right), \mathrm{Mg}(\mathrm{Ap})$ e $\mathrm{Zn}(\mathrm{Ap})$, indicando que estes elementos estão associados, quase que exclusivamente, aos microagregados.

Moura Filho \& Buol (1976) observaram importante reserva de nutrientes protegida dentro de microagregados de Latossolos Vermelhos, devido ao fato de estas estruturas serem fortemente estáveis e perenes. Os microagregados estáveis de tamanho 200-20 $\mu \mathrm{m}$ podem atuar como importante reserva de nutrientes, principalmente em solos cultivados, devido à sua
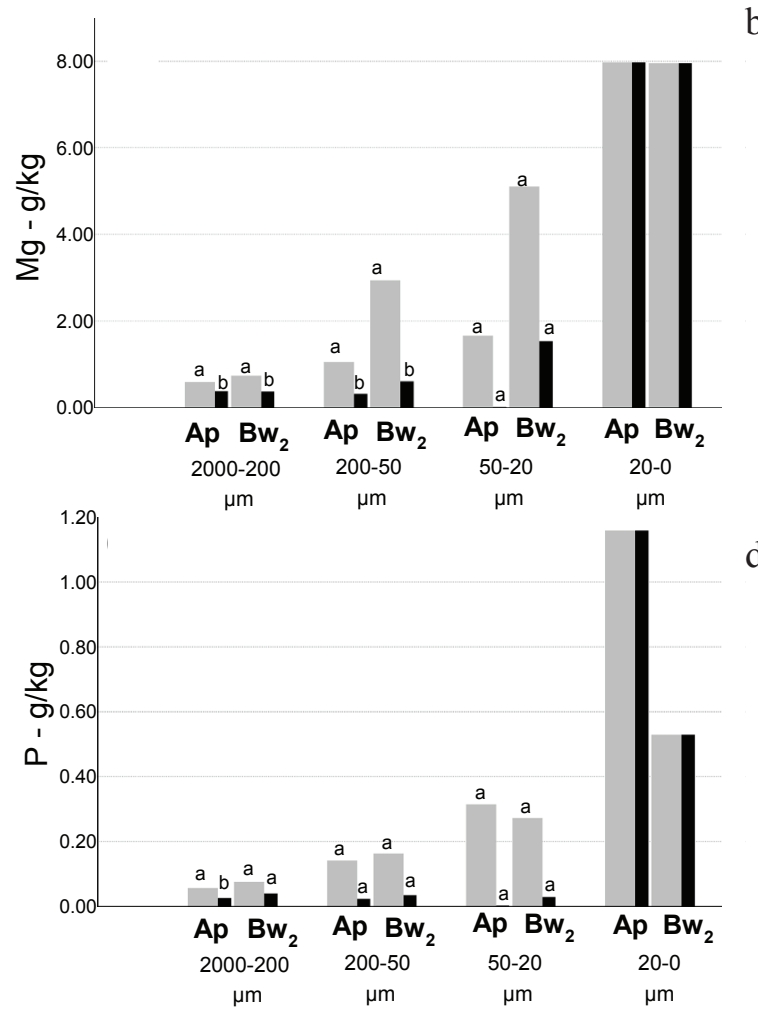

$\mathrm{d}$

Figura 5. Teores de potássio (a), magnésio (b), cálcio (c) e fósforo (d), nas frações separadas em função do tamanho das partículas, por meio de agitação em água (Fracionamento 1), e teores das frações após o procedimento de ultrassonificação (Fracionamento 2). A fração 20-0 $\mu \mathrm{m}$ foi submetida somente ao Fracionamento 1 (agitação em água). Barras seguidas de letras diferentes são, significativamente, diferentes, a 5\%, pelo teste $\mathrm{F}$ (Paracatu, MG, 2004). 

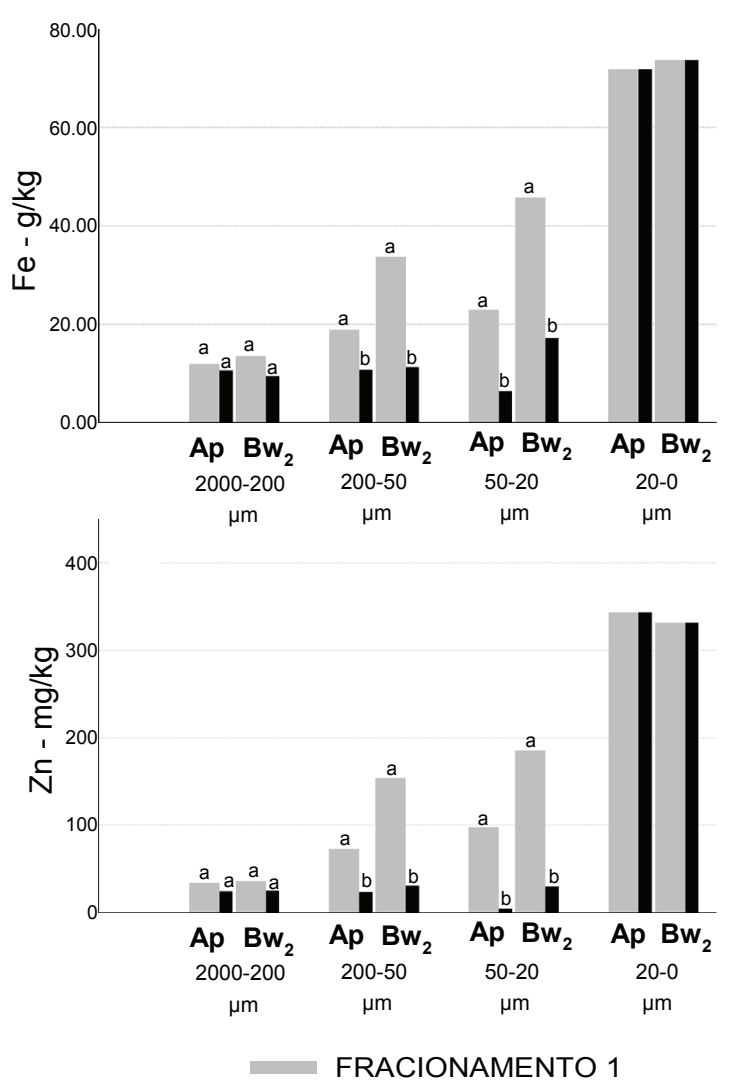

a

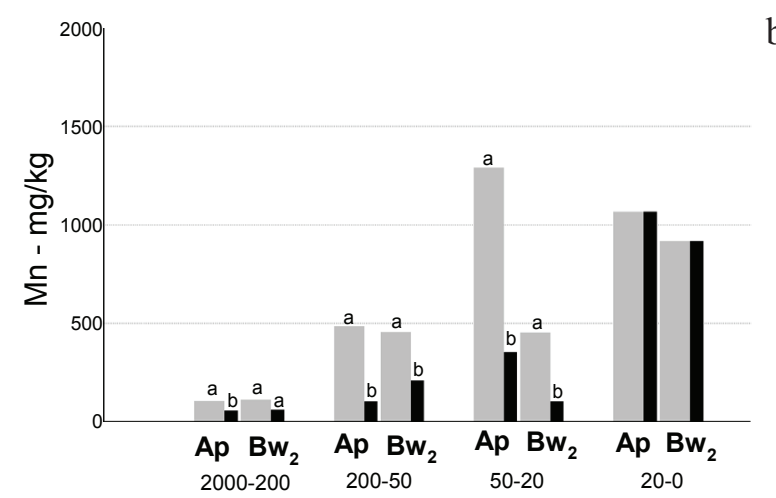

c

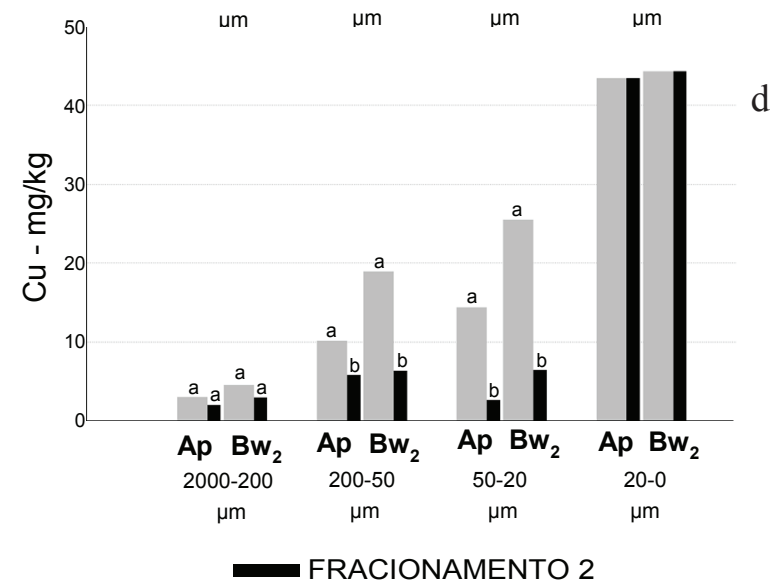

Figura 6. Teores de ferro (a), manganês (b), cobre (c) e zinco (d), nas frações separadas em função do tamanho das partículas, por meio de agitação em água (Fracionamento 1), e teores das frações após o procedimento de ultrassonificação (Fracionamento 2). A fração 20-0 $\mu \mathrm{m}$ foi submetida somente ao Fracionamento 1 (agitação em água). Barras seguidas de diferentes letras são diferentes, significativamente, a 5\%, pelo teste F (Paracatu, MG, 2004).

maior resistência à desagregação. Adesodun et al. (2007) observaram diminuição de $71 \%$ nos nutrientes disponíveis nos macroagregados $(4.760-250 \mu \mathrm{m})$ e de $6 \%$ nos microagregrados $(<250 \mu \mathrm{m})$, devido ao efeito de cultivo convencional. Da mesma forma, Pardo et al. (1997) encontraram maior depleção dos nutrientes disponíveis nos macroagregados $(4.000-200 \mu \mathrm{m})$, em comparação aos microagregados $(<250 \mu \mathrm{m})$.

Fatores de enriquecimento dos macro e micronutrientes

Na Tabela 3, são mostrados os teores de macro e micronutrientes, nas frações menores que $20 \mu \mathrm{m}$, recuperadas após o procedimento de ultrassonificação, e sua comparação, por meio dos fatores de enriquecimento, com teores das frações menores que $20 \mu \mathrm{m}$, separadas por agitação em água. $\mathrm{O}$ cálculo do fator de enriquecimento (FE) permite a comparação dos teores dos elementos nas frações $<20 \mu \mathrm{m}$, associadas às frações 200-50 $\mu \mathrm{m}$ e 50-20 $\mu \mathrm{m}$ (recuperadas com ultrassonificação), em relação às frações $<20 \mu \mathrm{m}$ do solo (separadas com agitação em água). Deste modo, pode-se avaliar a importância dos microagregados estáveis no enriquecimento de nutrientes, uma vez que se faz a comparação entre duas frações mais finas e, portanto, mais reativas, que se distinguem somente pela estabilidade física diferenciada: uma em formas fisicamente menos estáveis no solo (recuperadas por meio de dispersão em água) e outra em formas mais estáveis (recuperadas por meio de ultrassonificação).

De modo geral, os microagregados de tamanho 50-20 $\mu \mathrm{m}$ apresentam maior FE, quando comparados aos de tamanho $200-50 \mu \mathrm{m}$ e, portanto, maior potencial de acumulação e preservação dos nutrientes (Tabela 3). Agregados menores são mais estáveis, com relação à ação mecânica (preparo do solo, por exemplo), e menos expostos à perda de nutrientes e C neles acumulados e preservados (Pardo et al. 1997, Adesodun et al. 2007).

A difusão dos nutrientes, no sentido dos microagregados para a solução do solo, pode ser uma forma 
Tabela 3. Teores de macro e micronutrientes (média \pm erro padrão), nas frações menores que $20 \mu$ m, obtidas após a ultrassonificação das frações 200-50 $\mu \mathrm{m}$ e 50-20 $\mu \mathrm{m}$ (Fracionamento 3), e fatores de enriquecimentos (FE) ${ }^{1}$, em relação à fração menor que $20 \mu \mathrm{m}$, obtida por agitação em água (Paracatu, MG, 2004).

\begin{tabular}{|c|c|c|c|c|c|}
\hline \multirow{2}{*}{ Horizonte } & \multirow{2}{*}{$\begin{array}{c}\text { Fração } \\
\mu \mathrm{m}\end{array}$} & \multicolumn{2}{|c|}{$\longrightarrow \mathrm{P} \longrightarrow$} & \multicolumn{2}{|c|}{$\longrightarrow \mathrm{K}$} \\
\hline & & $\mathrm{g} \mathrm{kg}^{-1}$ & $\mathrm{FE}$ & $\mathrm{g} \mathrm{kg}^{-1}$ & $\mathrm{FE}$ \\
\hline \multirow{2}{*}{ Ap } & $200-50$ & $1,29 \pm 0,002$ & 1,12 & $23,88 \pm 0,004$ & 0,90 \\
\hline & $50-20$ & $1,45 \pm 0,001$ & 1,52 & $22,39 \pm 0,0534$ & 0,84 \\
\hline \multirow{2}{*}{$\mathrm{Bw}_{2}$} & $200-50$ & $0,55 \pm 0,001$ & 1,09 & $25,07 \pm 0,0084$ & 0,95 \\
\hline & $50-20$ & $0,77 \pm 0,001$ & 1,54 & $29,66 \pm 0,174$ & 1,04 \\
\hline \multirow{2}{*}{ Horizonte } & Fração & \multicolumn{2}{|c|}{$\mathrm{Ca}$} & \multicolumn{2}{|c|}{$\mathrm{Mg}$} \\
\hline & $\mu \mathrm{m}$ & $\mathrm{g} \mathrm{kg}^{-1}$ & $\mathrm{FE}$ & $\mathrm{g} \mathrm{kg}^{-1}$ & $\mathrm{FE}$ \\
\hline \multirow{2}{*}{ Ap } & $200-50$ & $1,89 \pm 0,002$ & 1,24 & $7,91 \pm 0,005$ & 0,99 \\
\hline & $50-20$ & $2,50 \pm 0,011$ & 1,63 & $7,64 \pm 0,028$ & 0,96 \\
\hline \multirow{2}{*}{$\mathrm{Bw}_{2}$} & $200-50$ & $0,27 \pm 0,001$ & 1,31 & $8,33 \pm 0,005$ & 1,05 \\
\hline & $50-20$ & $0,27 \pm 0,001$ & 1,31 & $8,52 \pm 0,004$ & 1,07 \\
\hline \multirow{2}{*}{ Horizonte } & Fração & \multicolumn{2}{|c|}{$\longrightarrow \mathrm{Fe} \longrightarrow$} & \multicolumn{2}{|c|}{$\longrightarrow \mathrm{Mn}$} \\
\hline & $\mu \mathrm{m}$ & $\mathrm{g} \mathrm{kg}^{-1}$ & $\mathrm{FE}$ & $\mathrm{mg} \mathrm{kg}^{-1}$ & $\mathrm{FE}$ \\
\hline \multirow{2}{*}{ Ap } & $200-50$ & $88,19 \pm 0,130$ & 1,23 & $4114,96 \pm 24,2$ & 3,86 \\
\hline & $50-20$ & $76,79 \pm 0,039$ & 1,07 & $4362,95 \pm 140,5$ & 4,09 \\
\hline \multirow{2}{*}{$\mathrm{Bw}_{2}$} & $200-50$ & $80,23 \pm 0,036$ & 1,19 & $876,33 \pm 6,02$ & 0,96 \\
\hline & $50-20$ & $82,24 \pm 0,049$ & 1,22 & $976,03 \pm 2,75$ & 1,06 \\
\hline \multirow{2}{*}{ Horizonte } & Fração & \multicolumn{2}{|c|}{$\mathrm{Cu}$} & \multicolumn{2}{|c|}{$\mathrm{Zn}$} \\
\hline & $\mu \mathrm{m}$ & $\mathrm{mg} \mathrm{kg}^{-1}$ & FE & $\mathrm{mg} \mathrm{kg}^{-1}$ & $\mathrm{FE}$ \\
\hline \multirow{2}{*}{ Ap } & $200-50$ & $46,96 \pm 0,864$ & 1,08 & $467,51 \pm 2,4$ & 1,36 \\
\hline & $50-20$ & $55,05 \pm 0,647$ & 1,27 & $435,05 \pm 17,9$ & 1,27 \\
\hline \multirow{2}{*}{$\mathrm{Bw}_{2}$} & $200-50$ & $51,05 \pm 0,396$ & 1,25 & $408,29 \pm 3,0$ & 1,23 \\
\hline & $50-20$ & $59,65 \pm 1,181$ & 1,44 & $450,75 \pm 39,2$ & 1,36 \\
\hline
\end{tabular}

${ }^{1} \mathrm{FE}=$ (teores das frações menores que $20 \mu \mathrm{m}$, associadas às frações maiores e recuperadas pela ultrassonificação)/(teor da fração menor que 20 um do solo, obtido pela agitação em água).

de mobilidade intra-agregados, condicionada pelos maiores valores de FE, uma vez que tais nutrientes, principalmente os mais móveis, sofrem contínua depleção na solução do solo, pelo processo de lixiviação. Tokunaga et al. (2001) estudaram a difusão de $\mathrm{Cr}$, ao longo da escala dos agregados, mostrando redução na mobilidade, com a presença de matéria orgânica intra-agregados, que possui a capacidade de adsorção de Cr. Da mesma forma, a baixa mobilidade de $\mathrm{P}, \mathrm{Cu}, \mathrm{Mn}$ e $\mathrm{Zn}$ provoca a diminuição do seu processo difusivo (Axe \& Trivedi 2002). O P, Cu e Zn, em particular, são fortemente adsorvidos aos óxidos, na forma de adsorção específica, diminuindo sua mobilidade no solo. Em contrapartida, o $\mathrm{Mg}$ e $\mathrm{K}$ são adsorvidos eletrostaticamente, de forma mais fraca, condicionando-os a maior mobilidade. Em consequência disto, menores valores de FE, encontrados para o $\mathrm{K} \mathrm{e} \mathrm{Mg}$, e maiores valores, encontrados para o $\mathrm{P}, \mathrm{Cu}, \mathrm{Mn}$ e $\mathrm{Zn}$, sugerem o reflexo da mobilidade diferenciada destes elementos.
Teores e fatores de enriquecimento do carbono orgânico

Os teores de $\mathrm{C}$, nos microagregados de tamanho 50-20 $\mu \mathrm{m}$, no horizonte Ap, foram maiores do que aqueles associados à fração $<20 \mu \mathrm{m}$, obtida pela agitação em água, conforme evidenciam os valores FE (Tabela 4). Adicionalmente, estes microagregados (50-20 $\mu \mathrm{m})$ apresentaram teores superiores ao teor de carbono do solo (Tabela 1). Trabalhos prévios indicam que os microagregados possuem elevada capacidade de acúmulo de C (Six et al. 2002, Virto et al 2008). De fato, os macroagregados dependem de agentes cimentantes mais lábeis e mais facilmente expostos, sendo, então, menos estáveis e mais sensíveis ao manejo do solo (Tisdall \& Oades 1982). Em contrapartida, a proteção física no interior de microagregados, que possuem, adicionalmente, maior estabilidade, torna o $\mathrm{C}$ pouco acessível aos micro-organismos (Feller \& Beare 1997, Six et al. 
Tabela 4. Teores de carbono orgânico total (média \pm erro padrão), nas frações menores que $20 \mu \mathrm{m}$, obtidas após a ultrassonificação das frações $200-50 \mu \mathrm{m}$ e $50-20 \mu \mathrm{m}$ (Fracionamento 3), e fatores de enriquecimentos (FE) ${ }^{1}$, em relação à fração menor que $20 \mu \mathrm{m}$, obtida por agitação em água (Paracatu, MG, 2004).

\begin{tabular}{crcc}
\hline \multirow{2}{*}{ Hor } & \multirow{2}{*}{ Fração } & \multicolumn{2}{c}{ Carbono } \\
\cline { 3 - 4 } & & dag kg-1 & FE \\
\hline \multirow{2}{*}{ Ap } & $200-50 \mu \mathrm{m}$ & $2,85 \pm 0,085$ & 1,07 \\
& $50-20 \mu \mathrm{m}$ & $4,02 \pm 0,028$ & 1,51 \\
\multirow{2}{*}{$\mathrm{Bw}_{2}$} & $200-50 \mu \mathrm{m}$ & $0,75 \pm 0,007$ & 0,41 \\
& $50-20 \mu \mathrm{m}$ & $0,89 \pm 0,035$ & 0,45 \\
\hline
\end{tabular}

${ }^{1} \mathrm{FE}=$ (teores das frações menores que $20 \mu \mathrm{m}$, associadas às frações maiores e recuperadas pela ultrassonificação)/(teor da fração menor que $20 \mu \mathrm{m}$ do solo, obtido pela agitação em água).

2002, Denef et al. 2004, Virto et al. 2008). Além disto, a proteção química, ou seja, a adsorção dos ácidos orgânicos aos componentes da fração argila, potencializa a estabilidade do $\mathrm{C}$ associado à fase mineral dos microagregados, sendo esta proteção maior em solos oxídicos (Cerri et al. 1985). Virto et al. (2008), avaliando somente agregados do tamanho silte, encontraram teores de carbono de $0,99 \%$, em agregados do tamanho 50-20 $\mu \mathrm{m}$, no horizonte superficial de um Cambissolo de textura média e com predominância de argilominerais 2:1. Estes teores são menores do que os encontrados no horizonte superficial, no presente trabalho, sugerindo a ação mais efetiva da fração argila mais rica em óxidos e mais abundante.

Os menores teores de $\mathrm{C}$, nos microagregados no horizonte $\mathrm{Bw}_{2}$ (Tabela 3 ), apesar da maior presença destes microagregados neste horizonte, sugerem a ação mais efetiva de óxidos, como agente cimentante, quando o carbono está menos presente, conforme observado por Pinheiro-Dick \& Schwertmann (1996) e Muggler et al. (1999).

\section{Reserva de nutrientes associada aos microagregados}

Por meio dos teores e da participação em massa das diferentes frações obtidas pelo fracionamento utilizado, foi feita a avaliação da percentagem de nutrientes dos microagregados (tamanho 200-50 $\mu \mathrm{m}$ e 50-20 $\mu \mathrm{m}$ ), no conteúdo total do solo (Figura 7). As reservas apresentadas na forma de conteúdo fornecem uma ideia geral da distribuição dos nutrientes, nas diferentes frações e no solo como um todo. Em geral, a maior reserva de nutrientes está associada à fração $<20 \mu \mathrm{m}$, obtida por agitação em água, que corresponde à matriz mineral que compunha as estruturas pedológicas maiores, caracterizadas pela descrição morfológica do solo (Tabela 1).

As reservas das frações 2.000-20 $\mu \mathrm{m}$, do Fracionamento 2 (minerais presentes nas frações areia grossa, areia fina e silte grosso, livres de microagregados), tiveram menor participação na reserva

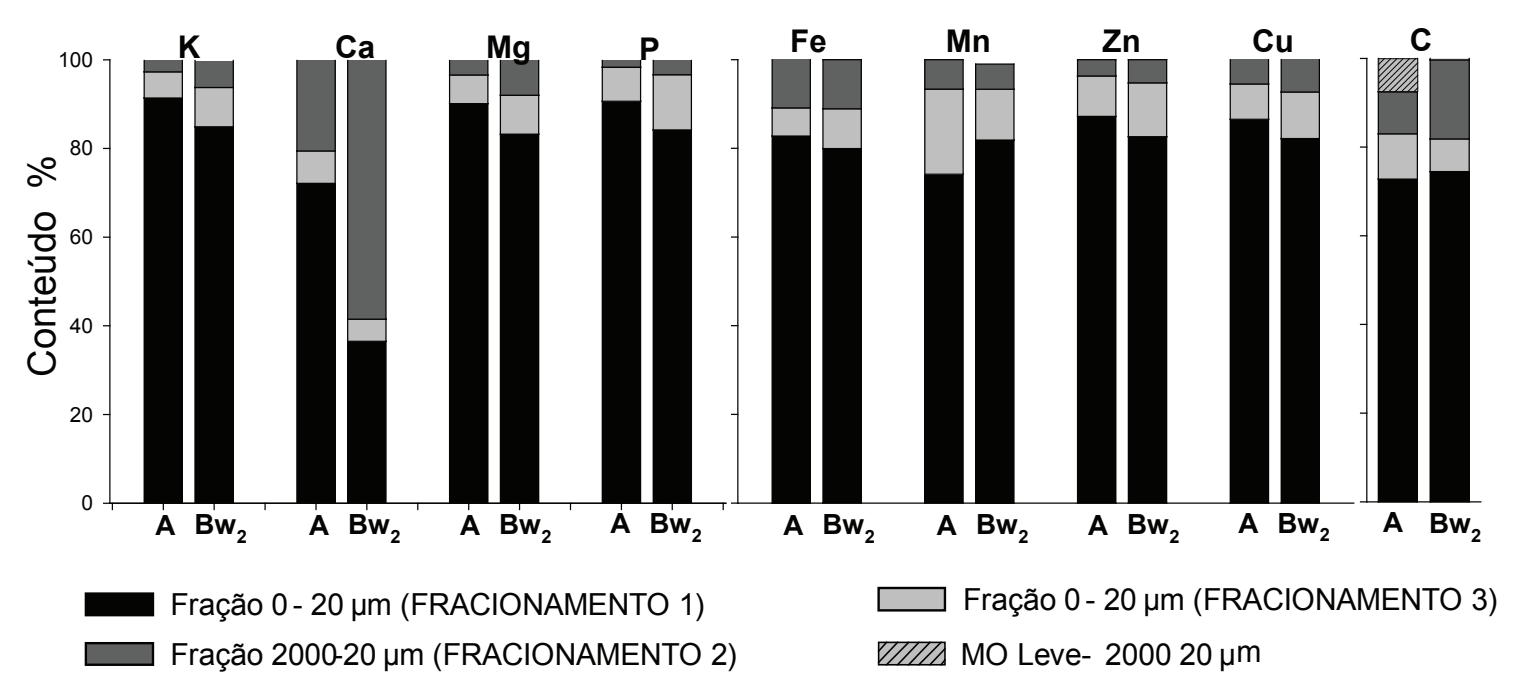

Figura 7. Percentagem da participação dos conteúdos, em relação ao total do solo, de carbono orgânico, macro e micronutrientes, da fração 2.000-20 $\mu \mathrm{m}$ (Fracionamento 2); das frações $<20 \mu \mathrm{m}$, separadas após o procedimento de ultrassonificação (Fracionamento 3); da fração < $20 \mu \mathrm{m}$, separada por agitação em água (Fracionamento 1); e da matéria orgânica leve, retirada por flotação em água e obtida após agitação em água (Fracionamento 1) (Paracatu, MG, 2004). 
de nutrientes do solo, sendo menos importantes que os microagregados. A exceção é o $\mathrm{Ca}$, que esteve associado, principalmente, às frações 2.000-20 $\mu \mathrm{m}$, do Fracionamento 2 (Figura 7). Possíveis minerais fontes de $\mathrm{Ca}$, como feldspatos; quartzo, na forma de silcrete; e micas foram identificados nestas frações, pelas análises de raios-X (dados não apresentados; Burak 2008).

A participação de macro e micronutrientes nos microagregados variou $5-19 \%$ do conteúdo total do solo, com o maior valor observado para o $\mathrm{Mn}$, no horizonte Ap, e o menor valor para o $\mathrm{Ca}$, no horizonte $\mathrm{Bw}_{2}$. Pequena reserva de nutrientes foi encontrada nos microagregados, em relação ao total. Contudo, tal reserva torna-se um compartimento estável, fisicamente, frente ao processo de desestruturação do solo, tornando-se importante como reserva de menor labilidade. Ao comparar estas reservas com as relacionadas às frações 2.000-20 $\mu \mathrm{m}$ (Fracionamento 2), fica claro que a maior parte dos nutrientes está associada aos microagregados, principalmente o $\mathrm{P}, \mathrm{Mn}, \mathrm{Zn}$ e $\mathrm{Cu}$.

A variabilidade em escala micrométrica é pouco considerada em estudos de diferentes compartimentos, para fins de fertilidade do solo. Dentro deste contexto, Houba et al. (1993) questionam a moagem do solo, para utilização do extrator resina em esfera, que apresentou maior extração, em comparação a outros extratores, em decorrência do aumento da superfície de exposição de P mais lábil, pela quebra de agregados. Semelhantemente, Rolim et al. (2008) encontraram menor correlação do $\mathrm{P}$ extraído com Mehlich-1 e resina em lâmina com $\mathrm{P}$, na planta, quando os solos foram moídos.

Com relação ao $\mathrm{C}$, foi observada participação de $7-11 \%$ do $\mathrm{C}$ associado aos microagregados do solo (Fracionamento 3), em relação ao C total do solo (Figura 5). Este $\mathrm{C}$ está associado à matéria orgânica de tamanho $<20 \mu \mathrm{m}$ e ao $\mathrm{C}$ mais fortemente associado à matriz mineral do solo (Figura 7). Já o $\mathrm{C}$ determinado nas frações 2.000-20 $\mu \mathrm{m}$ (Fracionamento 2) representa a matéria orgânica particulada de tamanho $>20 \mu \mathrm{m}$, correspondendo à matéria orgânica oclusa intra-agregados. A matéria orgânica leve, retirada por flotação em água, após agitação em água, teve participação de $7,5 \%$ e $0,3 \%$ do estoque total de C do solo, nos horizontes $\mathrm{Ap}$ e $\mathrm{Bw}_{2}$, respectivamente. A fração oclusa intra-agregados (matéria orgânica particulada de tamanho $>20 \mu \mathrm{m}$ - Fracionamento 2) correspondeu a $10 \%$ e $16 \%$ do total de carbono dos horizontes $\mathrm{Ap} \mathrm{e} \mathrm{Bw}_{2}$, respectivamente (Figura 7;
Fracionamento 2). A maior participação do carbono (70-75\%) ocorre na fração $<20 \mu \mathrm{m}$, obtida por agitação em água, correspondendo ao carbono fortemente associado à fração mais fina do solo, que compunha agregados maiores.

Denef et al. (2004) encontraram, em solos sob pastagem, carbono associado à fração mineral e ocluso intra-agregado, em solo de mineralogia oxídica, contribuindo com $46 \%$ do carbono total do solo. Esta contribuição passa para $44 \%$, em solo caulinítico, e para $16 \%$, em solo com predominância de minerais $2: 1$. Virto et al. (2008) encontraram $36 \%$ do $\mathrm{C}$ total do solo associado aos agregados de 50-20 $\mu \mathrm{m}$, sendo $28 \%$ associado à fração mineral intra-agregados e $8 \%$ ocluso intra-agregados.

Nos microagregados, o carbono sequestrado torna-se pouco alterável, com o manejo não conservacionista, sendo uma reserva altamente estável e física e quimicamente protegida da mineralização, pela microbiota do solo. Em contrapartida, o carbono relacionado à matéria orgânica leve torna-se mais acessível à biota do solo. Six et al. (2002) demonstraram que o tempo médio de residência do $\mathrm{C}$ em microagregados (proteção química e física), de um solo sob pastagem em clima tropical, é de, aproximadamente, 75 anos. Cerri et al (1985) demonstraram que a taxa de ciclagem do carbono, associado ao silte e argila (proteção química), é de, aproximadamente, 40 anos.

No presente trabalho, o carbono dos microagregados [associado à fração mineral intra-agregados (fração 0-20 $\mu \mathrm{m}$; Fracionamento 3) + ocluso intra-agregados (fração $>20 \mu \mathrm{m}$, obtida após ultrassonificação das frações 2.000-20 $\mu \mathrm{m}$; Fracionamento 2)] representa $21-24 \%$ do carbono total do solo, apontando a necessidade de preservação também dos macroagregados do solo, por meio de manejos conservacionistas, objetivando à manutenção da matéria orgânica do solo e à efetiva contribuição de uma agricultura sustentável, para a amenização do efeito estufa.

\section{CONSIDERAÇÕES FINAIS}

O estudo das frações granulométricas do solo permitiu concluir que grande parte dos macro e micronutrientes, associados às frações 200-50 $\mu \mathrm{m}$ e 50-20 $\mu \mathrm{m}$, separadas por agitação em água, são, de fato, microagregados desempenhando papel de acúmulo e preservação de nutrientes no solo. Apesar do baixo conteúdo destes nutrientes (5-19\%), a alta 
estabilidade destes agregados pode contribuir como um compartimento estável, frente a ações de degradação da estrutura física do solo. Este compartimento torna-se especialmente importante, em regiões de uso intensivo do solo, onde a mecanização agrícola pode resultar na quebra preferencial dos macroagregados que são menos estáveis e, consequentemente, mais vulneráveis à perda dos nutrientes intra-agregados. A capacidade de acúmulo de carbono nos microagregados foi baixa (21-24\%), porém, este carbono dificilmente torna-se disponível à mineralização, pela alta estabilidade dos microagregados, contribuindo, mais efetivamente, no sequestro de carbono, em situações onde a degradação da estrutura física do solo é mais intensa. Estudos futuros devem ser dirigidos para a labilidade e biodisponibilidade dos nutrientes preservados nos microagregados, para melhor elucidação do seu papel como reserva de nutrientes e sua ciclagem biogeoquímica.

\section{AGRADECIMENTOS}

Ao Conselho Nacional de Desenvolvimento Científico e Tecnológico (CNPq), pelo suporte ao projeto $n^{\circ} 475623 / 2003-7$, e à Coordenação de Aperfeiçoamento de Pessoal de Nível Superior (Capes), pelo financiamento do projeto, dentro do programa CAPES-COFECUB, projeto $\mathrm{n}^{\circ}$ 514-05. Este trabalho faz parte do projeto Embrapa Cerrados/IRD $\mathrm{n}^{\circ} 0203205$ (Mapeamento das Paisagens do Cerrado e

Funcionamento de Solos Representativos).

\section{REFERÊNCIAS}

ADESODUN, J. K.; ADEYEMI, E. F.; OYEGOKE, C. $O$. Distribution of nutrient elements within water-stable aggregates of two tropical agro-ecological soils under different land uses. Soil \& Tillage Research, Amsterdam, v. 92, n. 1/2, p. 190-197, 2007.

ANDERSON, R. J.; INGRAM, J. S. I. Tropical soil biology and fertility: a handbook of methods. Wallingford: CAB International, 1989.

AXE, L.; TRIVEDI, P. Intraparticle surface diffusion of metal contaminants and their attenuation in microporous amorphous $\mathrm{Al}, \mathrm{Fe}$, and $\mathrm{Mn}$ oxides. Colloid Interface Science, San Diego, v. 247, n. 2, p. 259-265, 2002.

AZEVEDO, A. C.; BONUMÁ, A. S. Partículas coloidais, dispersão e agregação em latossolos. Ciência Rural, Santa Maria, v. 34, n. 2, p. 609-617, 2004.

BALABANE, M.; PLANE, A. F. Aggregation and carbon storage in silty soil using physical fractionation techniques.
European Journal of Soil Science, Oxford, v. 55, n. 2, p. 415-427, 2004.

BALBINO, L. C. et al. Changes in porosity and microaggregation in clayed ferralsols of the Brazilian Cerrado. European Journal of Soil Science, Oxford, v. 53, n. 2, p. 219-230, 2002.

BALESDENT, J. ; PETRAUD, J. P.; FELLER, C. Effet des ultrasons sur la distribution granulométrique des matières organiques des sols. Science du Sol, Paris, v. 29, n. 2, p. 95-106, 1991.

BURAK, D. L. Geoquímica e distribuição de metais pesados em solos da região de Unaí, Paracatu e Vazante, MG. 2008. 210 f. Tese (Doutorado em Solo e Nutrição de Plantas)-Universidade Federal de Viçosa, Viçosa, 2008.

CAMBIER, P. Organisation des constituants et interactions physicochimiques au sein des microagrégats de sols: application au système ferralitique kaolinite-oxyde de fer. 1986. 223 f. Thèse (Docteur Science du Sol)-Université de Paris VI, Paris, 1986.

CERRI, C. C. et al. Application du traçage isotopique naturel en $13 \mathrm{C}$ à I'étude de la dynamique de la matiére organique dans les sols. Cahiers Recherche de l'Academie de Science de Paris, Paris, v. 300, n. 9, p. 423-428, 1985.

COOPER, M; VIDAL-TORRADO, P.; CHAPLOT, V. Origin of microaggregates in soils with ferralic horizons. Scientia Agricola, Piracicaba, v. 62, n. 3, p. 256-263, 2005.

DENEF, K. et al. Carbon sequestration in microaggregates of no-tillage soils with different clay mineralogy. Soil Science Society of America Journal, Madison, v. 68, n. 6, p. 1935-1944, 2004.

DICK, D. P; SCHWERTMANN, U. Microaggregates from oxisols and inceptisols: dispersion through elective dissolution and physico-chemical treatments. Geoderma, Amsterdam, v. 74, n. 1, p. 49-63, 1996.

DONAGEMMA, G. K. Pré-tratamento na análise textural visando à minimização do pseudo-silte em latossolos de Minas Gerais. 2000. 89 f. Dissertação (Mestrado em Solos e Nutrição de Plantas)-Universidade Federal de Viçosa, Viçosa, 2000.

DONAGEMMA, G. K. et al. Fósforo remanescente em argila e silte retirados de latossolos após pré-tratamentos na análise textural. Revista Brasileira de Ciência do Solo, v. 32, n. 4, p. 1785-1791, 2008.

EMPRESA BRASILEIRA DE PESQUISA AGROPECUÁRIA (Embrapa). Centro Nacional de Pesquisa de Solos. Manual de métodos de análise de solo. 2. ed. Rio de Janeiro: Embrapa, 1997.

EMPRESA BRASILEIRA DE PESQUISA AGROPECUÁRIA (Embrapa). Centro Nacional de 
Pesquisa de Solos. Sistema brasileiro de classificação de solos. Brasília, DF: Embrapa Produção de Informação; Rio de Janeiro: Embrapa Solos, 2006.

FELLER, C.; BEARE, M. H. Physical control of soil organic matter dynamics in the tropics. Geoderma, Amsterdam, v. 79, n. 1, p. 69-116, 1997.

FERREIRA, M. M.; FERNANDES, B.; CURI, N. Mineralogia da fração argila e estrutura de latossolos da região Sudeste do Brasil. Revista Brasileira de Ciência do Solo, Campinas, v. 23, n. 3, p. 507-514, 1999.

FONSECA, G. C. et al. Atributos físicos, químicos e biológicos de Latossolo Vermelho distrófico de Cerrado sob duas rotações de cultura. Pesquisa Agropecuária Tropical, Goiânia, v. 37, n. 1, p. 22-30, 2007.

HOUBA, V. G. H.; CHARDON, W. J.; POESE, $\mathrm{K}$. Influence of grinding of soil apparent chemical composition. Communication of Soil Science and Plant Analysis, London, v. 24, n. 13/14, p. 1591-1602, 1993.

INDA JÚNIOR, A. V.; KÄMPF, N. Avaliação de procedimentos de extração dos óxidos de ferro pedogênicos com ditionitocitrato-bicarbonato de sódio. Revista Brasileira de Ciência do solo, Viçosa, v. 27, n. 6, p. 11391147, 2003.

JASTROW, J. D.; BOUTTON, T. W.; MILLER, R. M. Carbon dynamics of aggregate-associated organic matter estimated by carbon-13 natural abundance. Soil Science Society of America Journal, Madison, v. 60, n. 3, p. 801807, 1996.

LEMOS, R. C.; SANTOS, R. D. Manual de descrição e coleta de solo no campo. 4. ed. Viçosa: Sociedade Brasileira de Ciência do Solo, 2002.

MOURA FILHO, W.; BUOL, S. W. Studies of Latosol Roxo (Eutrustox) in Brazil: micromorphology effect on ion release. Experientiae, Viçosa, v. 21, n. 8, p. 161-177, 1976.

MUGGLER, C. C. et al. Aggregation, organic matter, and iron oxide morphology in oxisols from Minas Gerais, Brazil. Soil Science, Baltimore, v. 164, n. 10, p. 759-770, 1999.

NOVAIS, R. F.; SMYTH, T. J. Fósforo em solo e planta em condições tropicais. Viçosa: UFV, 1999.

PARDO, M. T.; GIAMPAOLO, S.; ALMENDROS, G. Effect of cultivation on physical speciation of humic substances and plant nutrients in aggregate fractions of crusting soil from Zimbabwe. Biology and Fertility of Soils, Berlin, v. 25, n. 1, p. 95-102, 1997.

PASSOS, R. R. et al. Carbono orgânico e nitrogênio em agregados de um Latossolo Vermelho distrófico sob duas coberturas vegetais. Revista Brasileira de Ciência do Solo, Viçosa, v. 31, n. 5, p. 1109-1118, 2007.
ROLIM, M. V. et al. Efeito da moagem do solo no teor de fósforo disponível por Mehlich-1, resina em esferas e em lâmina. Revista Brasileira de Ciência do Solo, Viçosa, v. 32, n. 3, p. 1181-1190, 2008.

ROSCOE, R.; BUURMAN, P.; VELTHORST, E. J. Disruption of soil aggregate by different amounts of ultrasonic energy in SOM fractionation of a clay Latosol: carbon, nitrogen, and $13 \mathrm{C}$ distribution in particle-size fractions. European Journal of Soil Science, Oxford, v. 51, n. 3, p. 445-454, 2000.

SCHAEFER, C. E. G. R. Microstructure of latosols as long-term biotic constructs. Australian Journal of Soil Research, Collingwood, v. 39, n. 5, p. 909-926, 2001.

SCHWERTMANN, U.; KODAMA, H.; FISCHER, W. R. Mutual interactions between organic and iron oxides. In: HUANG, P. M.; SCHNITZER, M. (Eds.). Interactions of soil minerals with natural organics and microbes. Madison: Soil Science Society of America, 1986. p. 223-250.

SIX, J. et al. Soil organic matter, biota and aggregation in temperate and tropical soils: effects of no-tillage. Agronomie, Les Ulis, v. 22, n. 7/8, p. 755-775, 2002.

TISDALL, J. M.; OADES, J. M. Organic matter and water-stable aggregates in soils. Journal of Soil Science, Oxford, v. 33, n. 1, p. 141-163, 1982.

TOKUNAGA, T. et al. Chromiun diffusion and reduction in soil aggregates. Environmental Science \& Technology, Washington, DC, v. 35, n. 15, p. 3169-3174, 2001.

TRAPNELL, C. G.; WEBSTER, R. Microaggregates in red earths and related soils in East and Central Africa, their classification and occurrence. Journal of Soil Science, Baltimore, v. 37, n. 1, p. 109-123, 1986.

VIRTO, I.; BARRE, P.; CHENU, C. Microaggregation and organic matter storage at the silt-size scale. Geoderma, Amsterdam, v. 146, n. 1/2, p. 326-335, 2008.

VOLLAND-TUDURI, N. et al. Direct analysis of microaggregates shrinkage for drying: application to microaggregates from a Brazilian clayed Ferralsol. Comptes Rendus Géoscience, Paris, v. 336, n. 11, p. 1017 1024, 2004.

WALKLEY, A.; BLACK, I. A. An examination of the Degtjareff method for determining soil organic matter and proposed modification of the chromic acid titration method. Soil Science, Baltimore, v. 37, n. 1, p. 29-38, 1934.

WAN, Y.; El-SWAIFY, S. A. Sediment enrichment mechanisms of organic carbon and phosphorus in a wellaggregated Oxisol. Journal of Environmental Quality, Madison, v. 27, n. 1, p. 132-138, 1998. 